\title{
Community mobilisation for HIV prevention in India: What difference does it make?
}

\author{
Isabelle de Zoysa, ${ }^{1}$ Kevin O'Reilly ${ }^{2}$
}

This special issue brings together a series of papers on the implementation and evaluation of community mobilisation efforts among sex workers and other marginalised populations within Avahan, the India AIDS Initiative. Avahan was initiated in 2003 as an attempt to build an HIV prevention model at scale across the six high prevalence states in India. It used a flexible but target-driven approach derived from business to mobilise collaboration and drive rapid implementation on the ground. Within a few years, Avahan demonstrated that high levels of coverage of high impact interventions can be achieved with large numbers of people at risk. ${ }^{12}$ The states targeted in this project have populations greater than most countries; working at scale in these settings was indeed a tall challenge. A recent study suggested that Avahan succeeded in averting an estimated 100000 HIV infections by $2008 .^{3}$

Inspired by the pioneering work of the Sonagachi Project in the state of West Bengal, ${ }^{4}$ Avahan included specific measures to build community participation and mobilisation within its mandated package of HIV prevention interventions. As described in the papers in this issue by Wheeler et al and Galavotti et al, ${ }^{6}$ the project deliberately sought active participation of sex workers and other high-risk groups in service planning and delivery, implemented structural approaches to address significant concerns of daily life (such as social entitlements and violence), and supported activities to encourage community ownership and leadership of community-based groups and networks. The expectation was that these measures would improve HIV prevention outcomes by reducing the risk and vulnerability of high risk groups and improving the uptake and quality of services.

${ }^{1}$ Florence, Italy; ${ }^{2}$ World Health Organization, Geneva, Switzerland

Correspondence to Dr Isabelle de Zoysa, Lungarno Guicciardini 17, Florence 50125, Italy;

isabelledezoysa@gmail.com
Evaluations of the role played by community mobilisation in HIV prevention are scarce, and the conceptual and methodological challenges that they face are considerable. In this case, the challenge was even greater: Avahan did not include community mobilisation in its initial evaluation framework, and its otherwise substantial data collection and analysis effort was not designed to measure the contribution of community mobilisation to the desired project outcomes. ${ }^{7}$ However, relevant and useful data were collected through a range of project monitoring and evaluation approaches, including integrated biological and behavioural surveys and behavioural tracking surveys. Some specific tools were also used to measure levels of community mobilisation, to assess progress and guide future activities. ${ }^{8}$ More systematic analyses are now planned, using pathway analysis, to assess the contribution of community mobilisation to positive project outcomes. ${ }^{6}$

The collection of articles in this issue represent a valiant effort to overcome some large challenges: the practical challenge of assessing community mobilisation processes; the conceptual challenge of linking community mobilisation interventions to observed behaviour changes and key prevention outcomes; and the greater challenge of trying to compensate for the unfortunate failure to capture key indicators at the outset. In line with previous reports, ${ }^{4}$ it is suggested that female sex workers in diverse settings can be approached as a community and mobilised to counteract the multiple threats that they face and improve their lives. This is an important result, given that similar efforts in the past have floundered in the face of adversity. ${ }^{9}$ A number of measurable changes were noted including increased confidence in the sex workers' ability to negotiate condom use, in speaking up for their rights and in handling crises. ${ }^{10} 11$ There are encouraging indications that sex workers who were associated with the community mobilisation activities were more likely to use services such as clinical services for care of sexually transmitted infections. ${ }^{11}$ This should contribute to increasing the programme coverage and enhancing its quality. Finally sex workers who were exposed to the intervention, reported an increase in consistent condom use and this will hopefully contribute to reduced HIV risk. ${ }^{12} 13$

Critics will identify a number of methodological issues with the data collection and analytical approaches. Ideally, interventions delivered at the community level such as the ones considered here should be evaluated at the community level and not through individual-level measurements and analyses - though this raises many challenges and is rarely done. ${ }^{14}$ In most of the studies presented in this issue, the reliance on observational designs and the lack of appropriate controls are further hampered by the general absence of time trends, given that relevant indicators were only introduced into monitoring and evaluation activities at a late stage of project implementation. Most comparisons are therefore made between intervention adopters and non-adopters. This approach measures the benefit to an individual of taking up the intervention. However, reported behaviours such as using condoms or supporting another sex worker in a crisis are sensitive to biases associated with programme exposure. Furthermore, analytical techniques cannot rule out reverse causality or confounding.

Briefly, a patchwork of results can be found in these papers that suggests, more than it demonstrates, important linkages between participation in a community mobilisation intervention and behavioural as well as a few selected health outcomes. From the perspective of clinical trial proponents seeking results in terms of HIV incidence reductions, this may seem too little. But for the evaluation of a programmatic effort on a truly larger scale, the evidence of effectiveness presented here approaches the thresholds for adequacy and plausibility that have been highlighted for such efforts. ${ }^{15} 16$ Individually, each study can be criticised for one or another methodological flaw, but the results obtained through a triangulation of data from multiple sources are consistent and plausible. They come together as a body of experience to enhance our understanding of how communities can be strengthened to confront the threat of HIV.

The identification of the study design and analysis concerns should not serve as an excuse "to throw the baby out with the bathwater' and dismiss the principles at 
stake. We should not lose sight of the fact that some basic community support measures are ethically mandated within HIV programmes among disenfranchised populations, given the huge social inequalities, health inequities and human rights violations that they face. The issue is not whether to implement the interventions concerned but rather how best to implement them, to ensure that they do adequately serve people's needs and to maximise their impact on HIV-related outcomes. Bringing definitive answers to these complex questions will not be easy. Einstein's words come to mind: "Not everything that counts can be counted, and not everything that can be counted counts."

Avahan should be applauded for taking community support processes to scale as part and parcel of their HIV prevention effort, and for tackling the challenge of 'navigating the swampy lowland' of evaluation $^{6}$ to verify critical assumptions about the pathways by which community mobilisation can make a difference. We look forward to more systematic analyses, but in the meantime, there is much that others working in the field of AIDS, and health and development in general, can learn from the conceptual and methodological work on community mobilisation that is reported here.

Isabelle de Zoysa is a co-chair (with Ties Boerma) of the Evaluation Advisory Group of the Avahan India AIDS Initiative.

Contributors Both authors contributed to the writing of the editorial.
Competing interests None.

Provenance and peer review Commissioned; internally peer reviewed.

Published Online First 5 July 2012

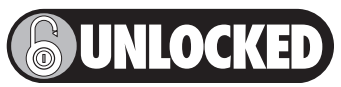

This paper is freely available online under the BMJ Journals unlocked scheme, see http://jech.bmj.com/site/ about/unlocked.xhtml

J Epidemiol Community Health 2012;66:ii1-ii2. doi:10.1136/jech-2012-201532

\section{REFERENCES}

1. Ramakrishnan L, Gautam A, Goswami $P$, et al. Programme coverage, condom use and STI treatment among FSWs in a large-scale HIV-prevention programme: results from cross-sectional surveys in 22 districts in southern India. Sex Transm Infect 2010;86(Suppl 1):i62-8.

2. Verma R, Shekar A, Khobragade S, et al. Scale-up and coverage of Avahan: a large-scale HIV-prevention programme among female sex workers and men who have sex with men in four Indian states. Sex Transm Infect 2010;86(Suppl 1):i76-82.

3. $\mathbf{N g} \mathbf{M}$, Gakidou E, Levin-Rector A, et al. Assessment of population-level effect of Avahan, an HIVprevention initiative in India. Lancet 2011;378:1643-52.

4. Jana S, Basu I, Rotheram-Borus MJ, et al. The Sonagachi Project: a sustainable community intervention programme. AIDS Educ Prev 2004;16:405-14.

5. Wheeler T, Kiran U, Matangi J, et al. Learning about scale, measurement and community mobilization: reflections on the implementation of the Avahan HIV AIDS Initiative in India. J Epidemiol Community Health 2012;66:ii16-ii25.

6. Galavotti C, Wheeler T, Kuhlmann AS, et al. Navigating the swampy lowland: a framework for evaluating the effect of community mobilisation in female sex workers in Avahan, the India AIDS
Initiative. J Epidemiol Community Health 2012;66 ii9-ii15.

7. Chandrasekaran P, Dallabetta G, Loo V, et al. Evaluation design for large scale HIV prevention Programs: the case of Avahan, the India AIDS initiative. AIDS 2008;22(Suppl 5):S1-S15.

8. Thomas T, Naranayan P, Wheeler T, et al. Design of a community ownership and preparedness index: using data to inform community capacity development. J Epidemiol Community Health 2012;66:ii26-ii33.

9. Aasthana $\mathbf{S}$, Oostvogels R. Community participation in HIV prevention: problems and prospects for community-based strategies among female sex workers in Madras. Soc Sci Med 1996;43:133-48.

10. Gaikwad SS, Bhende A, Nidhi G, et al. How effective is community mobilisation in HIV prevention among highly diverse sex workers in urban settings? The Aastha intervention experience in Mumbai and Thane districts, India. J Epidemiol Community Health 2012;66:ii69-ii77.

11. Prabhakar P, Mishra R, Tucker S, et al. Mobilising community collectivisation among female sex workers to promote STI service utilisation from the government health care system in Andhra Pradesh, India. J Epidemiol Community Health 2012;66:ii62-iï.

12. Erausquin JT, Biradavolu M, Reed E, et al. Trends in condom use among female sex workers in Andhra Pradesh, India: the impact of a community mobilization intervention. J Epidemiol Community Health 2012;66:ii49-ii54.

13. Guha M, Baschieri A, Bharat $S$, et al. Risk reduction and perceived collective efficacy among female sex workers in Tamil Nadu and Maharashtra, India: the importance of context. J Epidemiol Community Health 2012;66:ii55-ii61.

14. Kirkwood BR, Cousens SN, Victora CG, et al. Issues in the design and interpretation of studies to evaluate the impact of community-based interventions. Trop Med Int Health 1997;2:1022-9.

15. de Zoysa I, Habicht J-P, Pelto G, et al. Research steps in the development and evaluation of public health interventions. Bull WHO 1998;76:127-33.

16. Habicht JP, Victoria CG, Vaughan JP. Evaluation designs for adequacy, plausibility and probability of public health performance and impact. Int J Epidemiol 1999;28:10-18. 